\title{
Typen ja fosforin peltotase savimaan muokkauksen keventyessä
}

\author{
Laura Alakukku $^{1)}$, Antti Ristolainen ${ }^{2)}$ ja Tapio Salo ${ }^{2)}$ \\ ${ }^{1)}$ Helsingin yliopisto, Maataloustieteiden laitos, laura.alakukku@helsinki.fi \\ ${ }^{2)}$ MTT, Maa-ja elintarviketalouden tutkimuskeskus, Kasvintuotannon tutkimus, antti.ristolainen@mtt.fi, \\ tapio.salo@mtt.fi
}

\section{Tiivistelmä}

Kahdessa pitkäaikaisessa savimaan kenttäkokeessa tutkittiin ohran typpi- ja fosforitasetta muokkausintensiteetin vähetessä kynnöstä suorakylvöön. Kentät perustettiin Jokioisiin aito- ja hiuesavimalle vuosina 2000 ja 2001. Verratut muokkausmenetelmät olivat käytännön viljelyssä yleisimpiä. Syysmuokkauskäsittelyt olivat: kyntö (20-25 cm syvyyteen, P), sänkimuokkaus $(10-15 \mathrm{~cm}$, S) ja pellon jättäminen sängelle (keväällä suorakylvö, N). Keväällä aitosavimaan kokeessa kasvusto perustettiin kolmella tavalla: (A) jyrsinkylvö (yhden ajokerran menetelmä, tavallinen kylvölannoitin, (B), kylvö kevennettyyn muokkaukseen suunnitellulla koneella (kiekkovantaat, siemen ja lannoite sijoitettiin eri riveihin, (T) kylvö suorakylvökoneella (kaksoiskiekkovantaat, siemen ja lannoite sijoitettiin samaan riviin). Hiuesavimaan kokeessa koetekijät olivat PA, SA ja NT. Vuonna 2003 kokeissa viljeltiin kauraa (Avena sativa, Roope) ja muina vuosina kaksitahoista ohraa (Hordeum vulgare, Saana). Vuosittainen typpilannoitus oli 90-120 kg/ha ja fosforilannoitus 8-23 kg/ha. Keskimäärin vuosittainen typpilannoitus oli koetekijöittäin A 97, B 100 ja T 102 kg/ha. Vastaavasti fosforilannoitus oli keskimäärin 15-16 kg/ha/a. Vuosina 2000-2007 kokeissa laskettiin satotulosten ja sadosta tehtyjen ravinneanalyysien perusteella viljanviljelyn typen ja fosforin peltotase (lannoitus+laskeuma+kylvösiemenen ravinnemäärä siemensadossa korjattu ravinnemäärä) koetekijöittäin.

Hiuesavimaan kokeessa muokkaustapa ei vaikuttanut merkitsevästi siemen- ja ravinnesatoon koejakson aikana. Kynnetyn koetekijän typpisato oli kuitenkin keskimäärin $2-5 \%$ kevyemmin muokattuja koetekijöitä suurempi. Aitosavimaan kokeessa suorakylvettyjen koetekijöiden (NB, NT) siemen-, typpi- ja fosforisato olivat 8-14 \% pienemmät kuin kynnettyjen tai sänkimuokattujen koetekijöiden sadot. NB ja NT koetekijöiden keskisatoja laski merkittävästi poikkeuksellisen sateisen vuoden satotappiot. Erot ravinnetaseissa johtuivat pääosin eroista jyväsadoissa. Koejakson alkuvuosina suorakylvettyjen (NB ja NT) koetekijöiden ravinnetasetta nosti myös jyrsinkylvettyjä koetekijöistä suurempi lannoite- ja siemenmäärä. Tulokset vahvistavat käsitystä, että hyvä maan rakenne on avaintekijä, kun muokkausta kevennetään.

Asiasanat: kyntö, ohra, sato, suorakylvö, sänkimuokkaus 


\section{Johdanto}

Kevennetyn muokkauksen ja suorakylvön suosio kas voi nopeasti tämän vuosisadan alussa. Vuonna 2008 suorakylvöala oli 162000 ha eli n. $13 \%$ viljojen ja rypsin yhteenlasketusta viljelyalasta (TIKE 2009). Kevennetyn muokkauksen pinta-alaa ei ole tilastoitu, mutta arvioimme sen olevan 250 000-300 000 ha. Viljelijät siirtyvät kynnöstä sänkimuokkaukseen ja suorakylvöön säästääkseen aikaa ja kustannuksia. Muokkausta kevennetään myös talviaikaisen kasvipeitteisyyden lisäämiseksi kevätkylvöisten kasvien viljelyssä. Tavoitteena on vähentää pelloilta lähtevää eroosiota ja ravinnekuormitusta, josta n. $90 \%$ muodostuu kasvukauden (touko-elokuu) ulkopuolella (Puustinen ym. 2007).

Kasvipeite suojaa maan pintaa vesipisaroiden iskuilta sekä veden hiertävältä ja liuottavalta vaikutukselta. Suorakylvössä maata ei käsitellä sadonkorjuun ja kylvön välissä. Sen on todettu vähentävän vesieroosion ja partikkelihuuhtoutumisen riskiä boreaalisissa oloissa (mm. Skøien ym. 1995, Puustinen ym. 2005). Nykyisten ilmastonmuutosennusteiden (IPCC 2007) perusteella voidaan olettaa, että talviaikainen kuormitus tulee kasvamaan. Samalla tarve lisätä kasvukauden ulkopuolista kasvipeitteisyyttä kevätkylvöisten kasvien viljelyssä tulee suurenemaan.

Suomessa kevätviljojen ja öljykasvien viljely on keskittynyt Etelä- ja Länsi-Suomeen, jossa yli puolet peltoalasta on savimaita. Muokkaustapoja kehitettäessä tarvitaan ympäristövaikutusten ohella tietoa myös niiden vaikutuksesta kasvien sadontuottoon. Pohjoismaisten satotulosten mukaan siirtyminen syyskynnöstä sänkimuokkaukseen (kultivointi tai lautasäestys) on potentiaalinen tapa keventää savimaiden muokkausta kevätkylvöisten kasvien viljelyssä (Rydberg 1987, Børresen 1993, Pitkänen 1994, Aura 1999, Heinonen ym. 2002).

Monissa hankkeissa on tutkittu kevennetyn muokkauksen vaikutusta viljojen satoon (Rydberg 1987, Børresen 1993, Comia ym. 1994, Pitkänen 1994, Ekeberg ja Riley 1997, Aura 1999, Heinonen ym. 2002, Pietola ja Tanni 2003). Suorakylvön satovastetta on kuitenkin tutkittu sänkimuokkausta vähemmän pitkäaikaisissa kenttäkokeissa. Lisäksi pohjoismaisissa muokkauskokeissa on selvitetty harvoin eri menetelmien vaikutusta kasvien ravinteidenottoon ja ravinnetaseeseen. Tässä hankkeessa tutkittiin kahdessa pitkäaikaisessa muokkauskokeessa kevätviljojen sadonmuodostusta ja viljelyn ravinnetasetta. Savimaille perustetuissa kenttäkokeissa verrattiin syyskyntöä, -sänkimuokkausta ja suorakylvöä vuosina 2000-2007. Tutkimuksen tavoitteena oli selvittää, miten siirtyminen kynnöstä sänkimuokkaukseen tai suorakylvöön vaikuttaa kevätviljan sadon määrään sekä sen typen ja fosforin ottoon. Tätä tietoa tarvitaan, kun tarkastellaan muokkauksen keventämisen vaikutusta viljelyn ravinnetaseeseen, ravinteiden huuhtoutumisriskiin ja kasvihuonekaasupäästöihin.

\section{Aineisto ja menetelmät}

Kenttäkokeet perustettiin kahdelle hienojakoisen maan lohkolle MTT:lle Jokioisiin. Savimaan kenttä perustettiin vuonna 2000. Kentän ruokamultakerroksen $(0-20 \mathrm{~cm})$ savespitoisuus oli keskimäärin 0,62 $\mathrm{g} / \mathrm{g}$, orgaanisen hiilen pitoisuus $0,027 \mathrm{~g} / \mathrm{g}, \mathrm{pH} 6,19$ ja helppoliukoisen fosforin (hapan $(\mathrm{pH} 4,65$ ) ammoniumasetaattiuutto) pitoisuus $18 \mathrm{mg} / 1$ maata. Vuonna 2001 perustetun hiuesavimaan kentän ruokamultakerroksen saves- ja orgaanisen hiilen pitoisuudet olivat 0,46 ja $0,025 \mathrm{~g} / \mathrm{g}, \mathrm{pH}$ 6,24 ja helppoliukoisen fosforin pitoisuus $21 \mathrm{mg} / \mathrm{l}$ maata.

Savimaan kenttä oli osaruutukoe, jossa pääruudun koetekijä oli syysmuokkaus: $(\mathrm{P})$ kyntö (työsyvyys $20-25 \mathrm{~cm}),(\mathrm{S})$ sänkimuokkaus kultivaattorilla $(10-15 \mathrm{~cm}),(\mathrm{N})$ ei muokkausta. Osaruudun (ala $6 \times 40 \mathrm{~m}^{2}$ ) koetekijä oli kevätmuokkaus ja kylvö: (A) jyrsinkylvö (yhdistetty kylvömuokkaus (vaakatasojyrsin) ja kylvö (kylvölannoitus, lannoite ja siemen omiin riveihinsä, laahavantaat)), (B) kylvölannoitus kiekkovannaskoneella, joka sijoitti lannoitteen ja siemenen omiin riveihinsä, (T) kylvölannoitus suorakylvökoneella (kaksoiskiekkovantaat), joka sijoitti lannoitteen ja siemenen samaan riviin. Hiuesavimaan kenttä oli osaruutukoe (ruudun ala $10 \times 25 \mathrm{~m}^{2}$, jonka koetekijät olivat: (PA) syyskyntö, jyrsinkylvö keväällä, (SA) syyssänkimuokkaus, jyrsinkylvö keväällä, (NT) suorakylvö keväällä esikasvin sänkeen. Molemmissa kokeissa oli neljä kerrannetta.

Molemmilla kentillä viljeltiin ohraa (Hordum vulgare, lajike Inari (2000) ja Saana (2001, 2002, 2004-2007)). Vuonna 2003 viljeltiin kauraa (Avena sativa, Roope). Tavoiteltu kylvötiheys oli 500 itävää siementä neliömetrille. Koejakson aikana typpi- ja fosforilannoitettiin (NPK lannoite) $90-120 \mathrm{~kg}$ N/ha ja 
8-23 kg P/ha. Keskimäärin A, B ja T koetekijöiden typpilannoitus oli 97, 100 ja $102 \mathrm{~kg} \mathrm{~N} / \mathrm{ha}$. Keskimääräinen fosforilannoitus oli 15,15 ja $16 \mathrm{~kg} \mathrm{P} / \mathrm{ha}$. Suorakylvökoneen kylvövantaiden riviväli oli $140 \mathrm{~mm}$ ja kahden muun kylvökoneen $125 \mathrm{~mm}$. Suorakylvökone sijoitti lannoitteen siemenen kanssa samaan riviin ja kaksi muuta konetta sijoittivat lannoitteet joka toisen siemenrivin väliin (lannoiterivien väli $25 \mathrm{~cm}$ ).

Syysmuokatut koetekijät tasausäestettiin keväällä ennen kylvöä. Ruutujen kylvö ajoitettiin maan kuivumisen mukaan. Vuosina 2000-2002 kaikki ruudut kylvettiin samana päivänä, vaikka sänkimaa kuivui syysmuokattuja hitaammin. Tasausäestys 2-10 päivää ennen kylvöä varmisti, että syysmuokatut maat säilyttivät sopivan kylvökosteuden. Vuosina 2003 ja 2004 toukokuun sademäärä oli 47 ja 25 mm keskimääräistä (35 mm) suurempi. Sateisuus hidasti sänkimaan kuivumista merkittävästi ja vuonna 2003 ne kylvettiin 7-21 päivää ja vuonna 2004 2-14 päivää myöhemmin kuin syysmuokatut ruudut. Savimaan kentältä siemensato korjattiin $43-63 \mathrm{~m}^{2}$ ja hiuesavimaan kentältä 27-38 $\mathrm{m}^{2}$ alalta. Puintikosteus määritettiin kuivaamalla $40 \mathrm{~g}$ näyte $105{ }^{\circ} \mathrm{C}: s s a(12 \mathrm{~h})$. Kuiva-aineen typpipitoisuus määritettiin Kjeldalin menetelmällä, jossa käytettiin Kjeltec Auto 1030 Analyzer laitetta (AOAC methods 1980). Kuiva-aineen fosforipitoisuus määritettiin kolorimetrisesti muunnetulla ammonium-vanadiittimolybdaatti menetelmällä (Gericke ja Kurmies 1952). Siemensadossa korjattu typpi- ja fosforisato laskettiin kertomalla kuiva-ainesato ravinnepitoisuudella. Vuosittainen ravinnetase laskettiin OECD:n ohjeen mukaan (OECD 2007) summaamalla maahan pannut ravinnemäärät (siemen, lannoite, ravinnelaskeuma $(2,0 \mathrm{~kg} \mathrm{~N} / \mathrm{ha}$ ja $0,1 \mathrm{~kg} \mathrm{P} / \mathrm{ha})$ ja vähentämällä niistä siemensadossa korjattu ravinnesato:

$$
\begin{aligned}
& \mathrm{N}_{\text {tase }}(\mathrm{kg} / \mathrm{ha})=\mathrm{N}_{\text {lannoitteessa }}(\mathrm{kg} / \mathrm{ha})+\mathrm{N}_{\text {siemenessä }}(\mathrm{kg} / \mathrm{ha})+2,0(\mathrm{~kg} / \mathrm{ha})-\mathrm{N}_{\text {siemensadossa }}(\mathrm{kg} / \mathrm{ha}) \\
& \mathrm{P}_{\text {tase }}(\mathrm{kg} / \mathrm{ha})=\mathrm{P}_{\text {lannoitteessa }}(\mathrm{kg} / \mathrm{ha})+\mathrm{P}_{\text {siemenessä }}(\mathrm{kg} / \mathrm{ha})+0,1(\mathrm{~kg} / \mathrm{ha})-\mathrm{P}_{\text {siemensadossa }}(\mathrm{kg} / \mathrm{ha})
\end{aligned}
$$

\section{Tulokset ja niiden tarkastelu}

Savimaan kentällä satoerot olivat suurimmat vuosina 2001 ja 2004 (kuva 1). Vuonna 2001 NT koetekijä kylvettiin liian syvään, mikä pienensi todennäköisesti satoa muihin koetekijöihin verrattuna. Kasvukausi 2004 oli selvästi keskimääräistä sateisempi. Touko-elokuun sademäärä oli 97 mm suurempi kuin vuosien 1970-2000 keskiarvo 252 mm. Keväällä sänkimaan hidas kuivuminen viivästytti kylvöä ja kasvukauden aikana savimaan hidas vedenläpäisevyys haittasi kasvuston kehitystä. Etenkin NB ja NT koetekijöissä kasvusto kellastui ja osittain pakkotuleentui maan märkyyden haitatessa juuriston hapen saantia ja ravinteidenottoa. Samanlaisia tuloksia on raportoitu aiemmissa suomalaisissa kevennetyn muokkauksen tutkimuksissa (Pitkänen 1994, Aura 1999, Heinonen ym. 2002, Pietola ja Tanni 2003).

Kenttien satotulokset esitetään kuvassa 1. Keväällä 2003 ja 2004 satoi keskimääräistä enemmän, mikä hidasti sänkimaan kuivumista ja viivästytti sen kylvöä. Vastaava tilanne on käytännön viljelyssä sateisina keväinä. Molemmilla kentillä kynnetyn ja sänkimuokatun välillä ei ollut merkittävää satoeroa. Hiuesavimaalla suorakylvetyn koetekijän sato ei poikennut syysmuokattujen sadosta (kuva 1). Savimaan kentällä sänkeen kylvettyjen koetekijöiden sato oli keskimäärin $5 \%$ pienempi kuin syysmuokattuun maahan kylvettyjen koetekijöiden sato. Sänkikylvössä kylvötapojen välillä oli eroa. Jyrsinkylvössä (NA) viljasato oli keskimäärin lähes sama kuin syysmuokattaessa (PA, SA). Suoraan sänkeen kylvettyjen koetekijöiden NB ja NT sato oli kuitenkin keskimäärin 8-9 ja 11-12 \% pienempi kuin syysmuokattujen (PA ja SA) koetekijöiden sato.

Alkukasvukaudesta 2006 ja 2007 oli pitkiä poutajaksoja. Savimaan kentällä sänkimuokattujen (S) koetekijöiden sato oli tuolloin keskimäärin $12 \%$ ja sänkeen kylvettyjen (N) $20 \%$ suurempi kuin kynnettyjen koetekijöiden (kuva 1). Todennäköisesti kynnetty maa kuivui muita nopeammin heikentäen kasvuston vedensaantia. Tulos tuki aiempia savimaan kenttien tutkimuksia, joiden mukaan syyssänkimuokattaessa (Pitkänen 1994) ja sänkeen kylvettäessä (Pietola ja Tanni 2003) viljasato oli keskimäärin suurempi kuin kynnettäessä, kun alkukasvukausi oli vähäsateinen.

Koevuosina ja koejakson keskimääräinen siemensadossa korjattu typpi- ja fosforisato esitetään kuvissa 2 ja 3. Koejakson keskiarvona viljan typpipitoisuudessa ei ollut koetekijöiden välillä tilastollisesti 


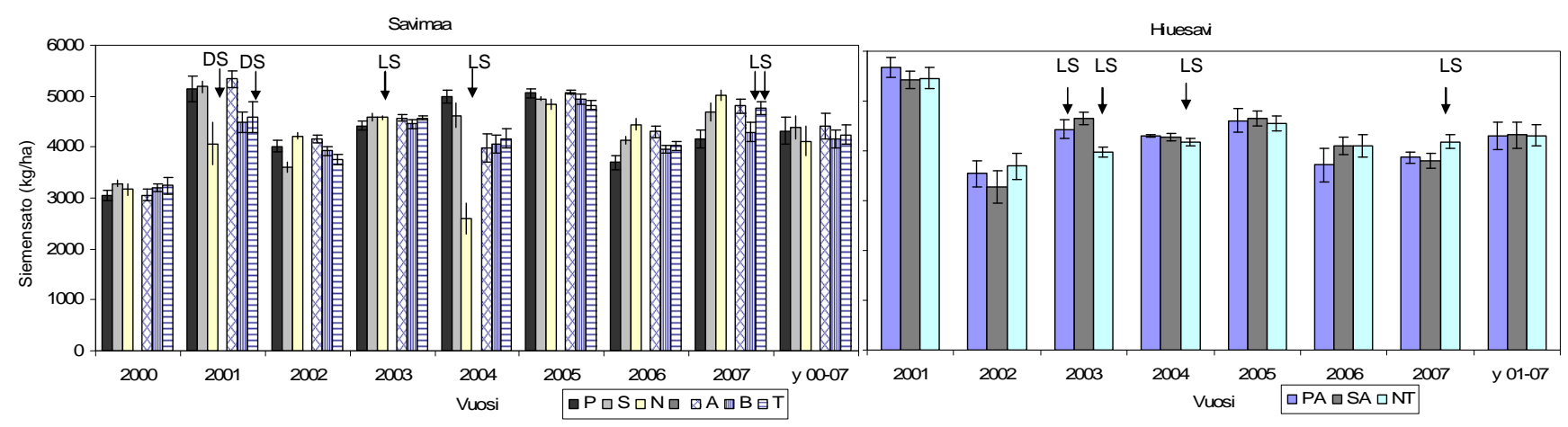

Kuva 1. Vuosittainen ja keskimääräinen kevätviljan siemensato $(0,14 \mathrm{~g} / \mathrm{g}$ kosteudessa) koejakson aikana savi- ja hiuesavimaan kentällä Jokioisissa. Janan pituus on kaksi kertaa keskiarvon keskivirhe ( \pm SE). Syysmuokkaus: $(\mathrm{P})$ kyntö, (S) sänkimuokkaus, (N) ei muokkausta. Kevätmuokkaus ja kylvö: (A) jyrsinkylvö (lannoite ja siemen omiin riveihinsä), (B) kylvölannoitus kiekkovannaskoneella (lannoite ja siemen omiin riveihinsä), (T) kylvölannoitus suorakylvökoneella (kaksoiskiekkovantaat, lannoitteen ja siemenen samaan riviin). Vuonna 2003 viljeltiin kauraa ja muina vuosina ohraa. Savimaan kenttä kalkittiin maaliskuussa 2005. DS, NT koetekijä kylvettiin liian syvään; LS, savimaan kentällä N koetekijä kylvettiin 7 (v. 2003) ja 14 (v. 2004) päivää muita koetekijöitä myöhemmin ja vuonna 2007 A ruudut kylvettiin kolme päivää muita ruutuja aikaisemmin. Hiuesaviman kentällä sänkimuokattu koetekijä kylvettiin yhdeksän päivää kyntöä ja 21 päivää sänkimaata aikaisemmin v. 2003. NT ruudut kylvettiin v. 2004 kaksi ja v. 2007 neljä päivää muita ruutuja myöhemmin.

merkitsevää eroa. Savimaan kentällä viljan typpipitoisuus oli kynnetyssä (P) koetekijässä 1,84 \%, sänkimuokatussa $(\mathrm{S})$ 1,97 \% ja sänkeen kylvetyssä $(\mathrm{N})$ 1,81\%. Hiuesavimaan kentällä vastaavat luvut olivat 2,00 (PA), 1,94 (SA) ja 1,89 \% (NT). Perusmuokkaustapojen väliset erot typpisadossa (kuva 2) johtuivat pääasiassa satoeroista (kuva 1).

Savimaan kentällä suoraan sänkeen kylvettyjen koetekijöiden typpisato oli keskimäärin 10-11\% (NB) ja 13-14 \% (NT) pienempi kuin syysmuokattujen koetekijöiden PA tai SA, vaikka sänkeen kylvettyjen koetekijöiden typpilannoitus oli vuosina 2000-04 syysmuokattuja suurempi (NB $4 \%$ ja NT 9 $\%)$. Sänkeen jyrsinkylvetyn koetekijän typpisato oli sen sijaan keskimäärin vain $2 \%$ pienempi kuin syysmuokattujen koetekijöiden PA ja SA. Vuosittain tarkasteltuna typpisato oli sänkeen kylvettäessä selvästi muita koetekijöitä pienempi runsassateisena kasvukautena (kuva 2), mikä tuki Pietolan ja Tannin (2003) tuloksia savimaan sänkeen kylvöstä. Maan märkyys viivästytti sänkeen kylvöä ja haittasi kasvuston kehitystä myöhemmin kasvukaudella pakkotuleennuttaen osan kasvustosta. Vesi imeytyi hitaasti sänkenä olleeseen savimaahan, jossa oli kynnöstä vähemmän suuria makrohuokosia (halkaisija > 0,3 mm, Alakukku ym. 2007). Lisäksi märästä sänkimaasta tuli todennäköisesti myös dityppioksiduulipäästöjä enemmän kuin kynnetystä maasta, kuten kentällä oli havaittu aiemmissa mittauksissa (Regina ym. 2007).

Koetekijöiden välillä ei ollut tilastollisesti merkitsevää eroa siemensadon fosforipitoisuudessa. Koetekijöiden välinen ero siemensadossa korjatussa fosforisadossa (kuva 3) johtui pääosin satoeroista niiden välillä (kuva 1). Savimaan kentällä NB ja NT koetekijöiden siemensadossa korjattu fosforisato oli keskimäärin 10-13 \% pienempi kuin syysmuokattujen PA ja SA koetekijöiden fosforisato, vaikka sänkeen kylvettyjen fosforilannoitus oli vuosina 2000-04 $4 \%$ (NB) tai $8 \%$ (NT) suurempi kuin muokattujen koetekijöiden. NB ja NT koetekijöiden muita pienempi keskimääräinen fosforisato johtui satoeroista vuosina 2001 ja 2004 (kuva 1).

Viljan viljelyn typen ja fosforin peltotaseet on esitetty kuvissa 2 ja 3. Typpi- ja fosforitaseet eivät poikenneet viljaviljelyalueen valtakunnallisista taseista (Salo ym. 2007, Uusitalo ym. 2007). Koejakson alkuvuosina 2000-04 B ja T koetekijöiden A koetekijää suurempi lannoite- ja siemenmäärä lisäsivät positiivista peltotasetta. Eniten koetekijöiden välistä eroa ravinnetaseessa kasvatti kuitenkin vuosien 2001 ja 2004 satoerot savimaan kentällä ja vuosien 2003 ja 2004 satoerot hiuesavimaan kentällä (kuvat 2 ja 3). Vuonna 2007 koekenttien fosforilannoitusta vähennettiin merkittävästi. Tästä huolimatta kenttien fosforisato oli samaa tasoa kuin muinakin koevuosina ja fosforitase oli selvästi negatiivinen (kuva 3). Molempien kenttien maan fosforitila oli hyvä ja tulevina vuosina kenttiä ei enää fosforilannoiteta. 

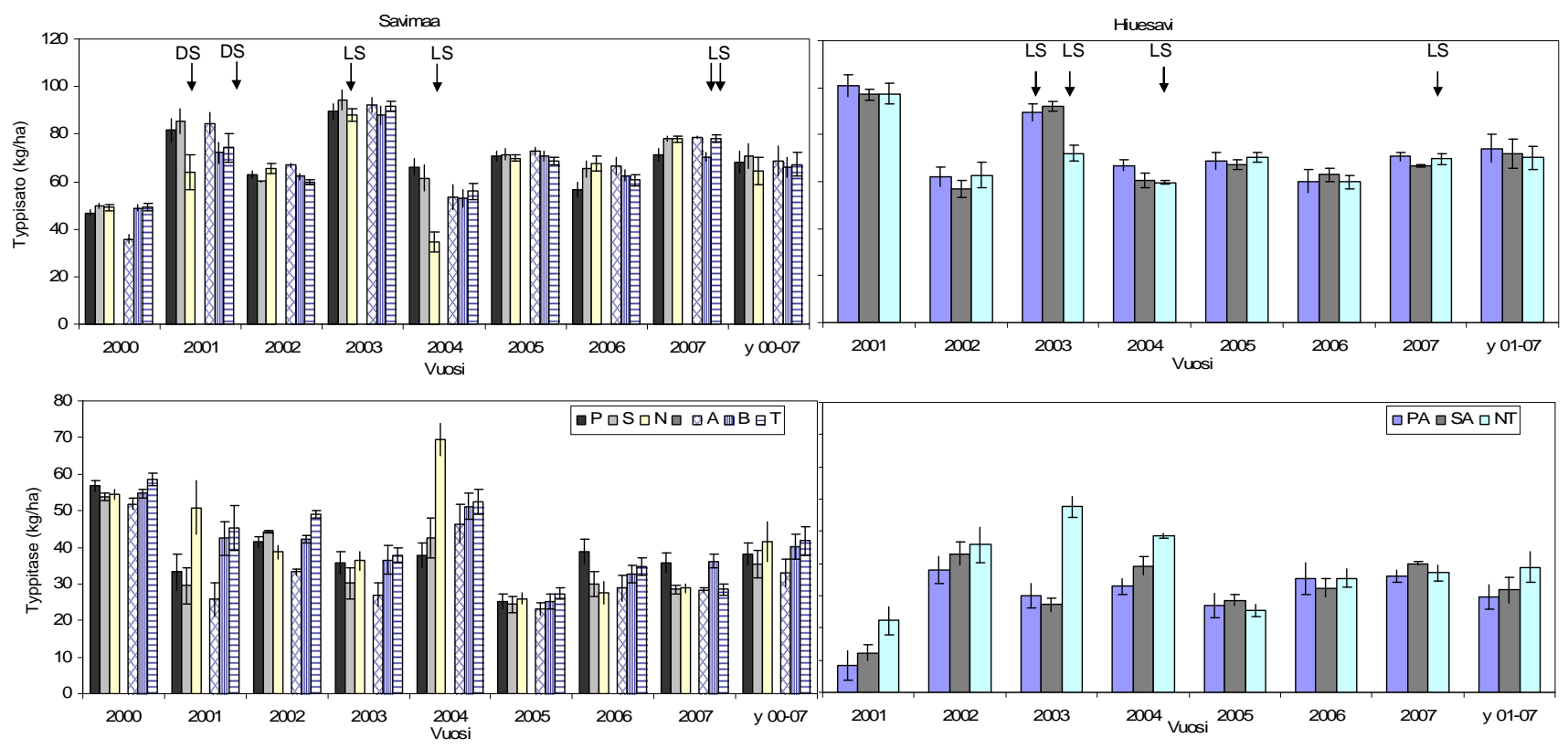

Kuva 2. Vuosittainen ja keskimääräinen kevätviljan siemensadossa korjattu typpisato (kuiva-aine) ja viljelyn typpitase (peltotase) koejakson aikana. Janan pituus \pm SE. Merkinnät kuten kuvassa 1.
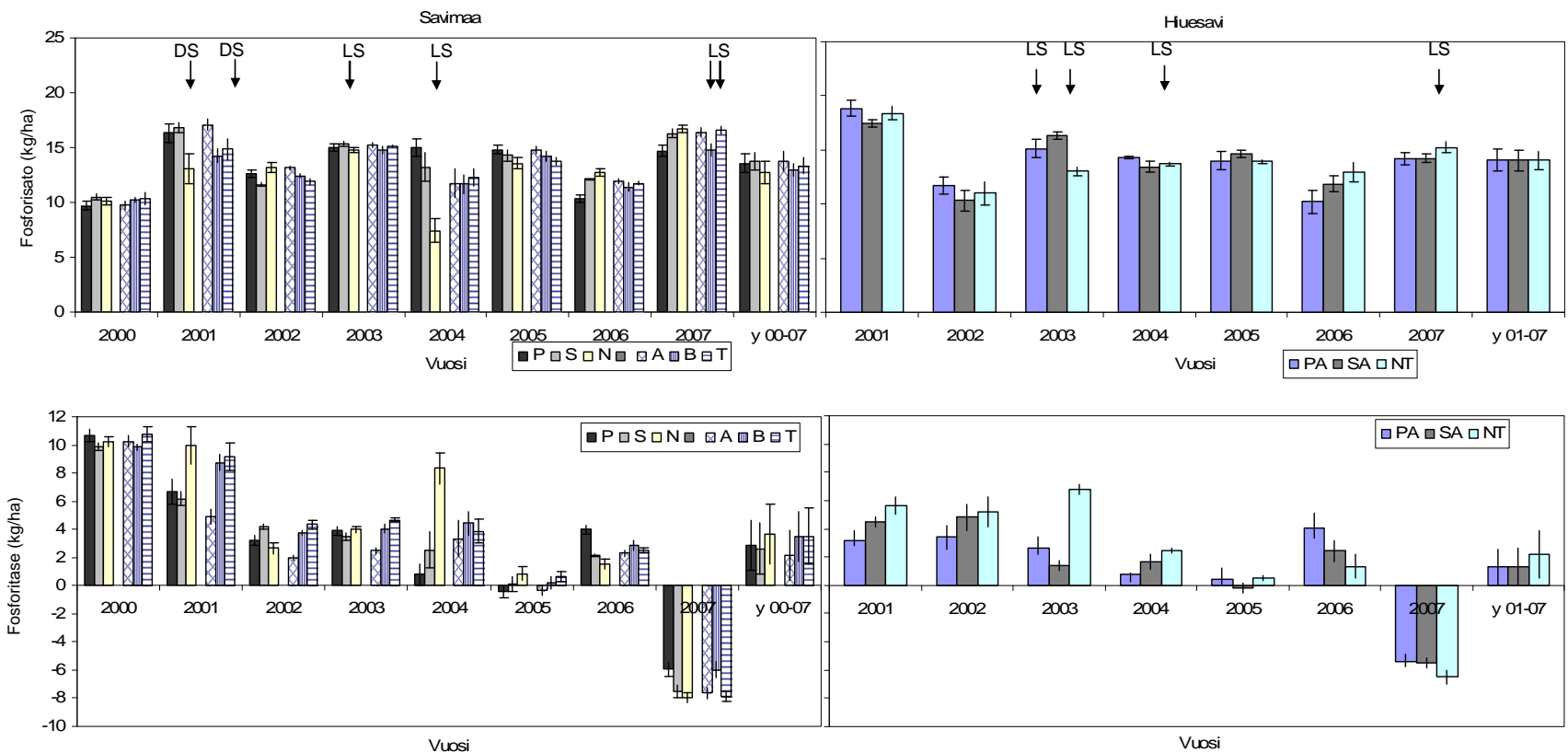

Kuva 3. Vuosittainen ja keskimääräinen kevätviljan siemensadossa korjattu fosfori (kuiva-aine) ja viljelyn fosforitase (peltotase) koejakson aikana. Janan pituus \pm SE. Merkinnät kuten kuvassa 1.

\section{Johtopäätökset}

Erot syysmuokkausten ja sänkeen kylvön välillä ohran siemen, typpi- ja fosforisadossa olivat pieniä, kun maan vedenläpäisevyys oli hyvä. Keskimääräistä sateisempina kasvukausina muokkaamattoman hitaasti vettä läpäisevän savimaan märkyys voi myöhästyttää kylvöä ja haitata kasvuston kehitystä merkittävästi. Kynnetyn savimaan ruokamultakerroksen hetkellinen veden varastointikyky on suurempi kuin kevyemmin 
muokattujen maiden. Tämä parantaa maan puskurointikapasiteettia vähentäen märkyyden aiheuttamia haittoja.

Perusmuokkaus ei vaikuttanut merkitsevästi ohran siemensadon typpi- ja fosforipitoisuuteen. Hiuesavimaan kokeessa kynnetyn koetekijän typpisato oli kuitenkin keskimäärin 2-5\% suurempi kuin sänkimuokatun tai sänkeen kylvetyn, koska ohran typpipitoisuus oli korkein kynnetyssä koetekijässä.

Perusmuokkaustapojen väliset satoerot vaikuttivat eniten eroihin typpi- ja fosforitaseessa. Tässä hankkeessa keskimääräistä peltotasetta kasvatti myös se, että kylvettäessä kiekkovantaisilla kylvökoneilla lannoite- ja siemenmäärä oli kokeen alkuvuosina suurempi kuin laahavannaskoneella kylvettäessä.

\section{Kirjallisuus}

Alakukku, L. Perälä, P. \& Regina, K. 2007. Structure of mouldboard ploughed and zero tilled topsoil. LandTechnik AgEng 2007. Engineering Solutions for Energy and Food Production. Conference: Agricultural Engineering, Hannover, November 09-10, 2007.VDI-Berichte Nr. 2001: 483-487.

AOAC methods. 1980. Thirteen edition, 7.021, 14.068.

Aura, E. 1999. Effects of shallow tillage on physical properties of clay soil and growth of spring cereals in dry and moist summers in southern Finland. Soil \& Tillage Research 50: 169-176.

Børresen, T. 1993. Ploughing and rotary cultivation for cereal production in a long-term experiment on a clay soil in southeastern Norway. 2. Yields and weed infestation. Soil \& Tillage Research 28: 109-121.

Comia, R.A., Stenberg, M., Nelson, P., Rydberg, T. \& Håkansson, I. 1994. Soil and crop responses to different tillage systems. Soil Tillage \& Research 29: 335-355.

Ekeberg, E., \& Riley, H.C.F. 1997. Tillage intensity effects on soil properties and crop yields in a long-term term on morainic loam soil in southeat Norway. Soil \& Tillage Research 42: 277-293.

Gericke, S. \& Kurmies, B. 1952. Phosphosäyre-bestimmung mit Ammonium Vanadat-Molybdat und ihre Anwendung in der Pflanzeanalyse. Zeitschr. Pflanzenernähr. Bodenk. 59: 235-247.

Heinonen, M., Alakukku, L. \& Aura, E. 2002. Effects of Reduced tillage and light tractor traffic on the growth and yield of oats (Avena sativa). Advances in Geoecology 35: 367-378.

IPCC. 2007. Climate Change 2007: Synthesis Report. 52 s. Available: http://www.ipcc.ch/pdf/assessmentreport/ar4/syr/ar4_syr.pdf

OECD 2007. OECD Nitrogen Balance Handbook, jointly published with Eurostat, Paris, France,

www.oecd.org/tad/env/indicators

Pietola, L., \& Tanni, R. 2003. Response of seedbed physical properties, soil $\mathrm{N}$ and cereal growth to peat application during transition to conservation tillage. Soil \& Tillage Research 74: 65-79.

Pitkänen, J. 1994. A long-term comparison of ploughing and shallow tillage on the yield of spring cereals in

Finland. In: Vol. II: Proceeding $13^{\text {th }}$ Conference International Soil Tillage Research Organization, Aalborg,

Denmark, July 24-29, s. 709-715.

Puustinen, M., Koskiaho, J. \& Peltonen, K. 2005. Influence of cultivation methods on suspended

solids and phosphorus concentrations in surface runoff on clayey sloped fields in boreal climate. Agriculture,

Ecosystems \& Environment 105: 565-579.

Puustinen, M., Tattari, S., Koskiaho, J. \& Linjama, J. 2007. Influence of seasonal and annual

hydrological variations on erosion and phosphorus transport from arable areas in Finland. Soil \& Tillage Research 93: 44-55.

Regina, K., Perälä, P. \& Alakukku, L. 2007. Greenhouse gas fluxes in boreal agricultural soils under conventional tillage and no-till practice. COST Action 639. Greenhouse-gas budget of soils under changing climate and land use (BurnOut). (EJandl, R. \& Olsson, M. eds.). Vienna 2007. s. 53-56.

Rydberg, T. 1987. Studies in ploughless tillage in Sweden 1975-1986. Raport Jordbearbetningsavdelning Sveriges Lantbrukuniversitet. Uppsala, no. 76.

Salo, T., Lemola, R. \& Esala, M. 2007. National and regional net nitrogen balances in Finland in 1990-2005. Agricultural and Food Science 16: 366-375.

Skøien,S., Børresen, T., Lundekvam, H. \& Uhlen, G. 1995. Effects of plant cover and tillage on soil erosion and phosphorus losses in surface runoff. In: Proceeding NJF seminar no. 245. The use of catch or cover crops to reduce leaching and erosion. Linden, B. (ed.). NJF-utredning/rapport nr 99. Knivsta, Sweden, 3-4 October 1994. s. 142-147.

TIKE. 2009. Matilda. http://www.matilda.fi/servlet/

Uusitalo, R., Turtola, E., Grönroos, J., Kivistö, J., Mäntylahti, V., Turtola, A., Lemola, R. \& Salo, T. 2007.

Finnish trends in phosphorus balances and soil test phosphorus. Agricultural and Food Science 16: 301-316. 